\title{
Impactos (turísticos ou não) nas comunidades indígenas brasileiras ${ }^{1}$
}

\section{Impacts (tourist or not) in Brazilian indigenous communities}

\author{
Sandra Dalila Corbari (CORBARI, S. D.) ${ }^{*}$ \\ Miguel Bahl (BAHL, M.) ${ }^{* *}$ \\ Silvana do Rocio de Souza (SOUZA, S. do R. de) *** $^{* *}$
}

RESUMO - Os impactos ou efeitos provocados pelo processo de desenvolvimento da atividade turística nas localidades receptoras são amplamente abordados na literatura sobre o turismo. Em alguns casos apontam-se os impactos negativos desse desenvolvimento como a mercantilização da cultura, a caricaturização do grupo visitado e de seus recursos tradicionais e o efeito demonstração. No entanto, o desenvolvimento turístico gera também efeitos positivos, como a valorização cultural, preservação e resgate de traços culturais e preservação do patrimônio. Com isso, para o presente artigo $^{2}$ se teve como objetivo geral "identificar quais seriam os agentes de potenciais mudanças socioculturais nas comunidades indígenas brasileiras" através da construção do marco teórico e, em seguida, da pesquisa documental, utilizando como base teses e dissertações brasileiras, publicadas entre 1999 e 2012, sobre o turismo envolvendo comunidades indígenas. Constatou-se com a pesquisa que o turismo estava sendo apenas um dos agentes de potenciais mudanças socioculturais, sendo outros tão ou mais impactantes quanto essa atividade, tais como ações de órgãos governamentais, instituições religiosas e o setor imobiliário.

Palavras-chave: Turismo; Comunidades indígenas; Impactos socioculturais; Brasil.

\footnotetext{
${ }^{1}$ Agradecemos ao CNPq pela concessão de uma bolsa que custeou parte da presente pesquisa, bem como ao Grupo de Pesquisa Turismo e Sociedade, ao qual está vinculada.

* Graduação e Mestrado em Turismo pela Universidade Federal do Paraná (UFPR) e doutoranda e bolsista CAPES pelo Programa de Pós-Graduação em Meio Ambiente e Desenvolvimento (UFPR). Email: corbari91@hotmail.com

*** Graduação em Turismo e Licenciaturas em Geografia e em Estudos Sociais pela Universidade Federal
do Paraná (UFPR). Mestrado e Doutorado em Turismo em Ciências da Comunicação pela Universidade
de São Paulo (USP). Estágio pós-doutoral desenvolvido na Universidade de Girona (Espanha). Professor
do Departamento de Turismo da UFPR junto ao curso de Graduação em Turismo e aos Programas de
Mestrado em Turismo e Mestrado e Doutorado em Geografia. E-mail: migbahl@ ufpr.br
**** Graduação em Turismo pela Universidade Federal do Paraná (UFPR). Mestrado em Educação pela
Universidade Tuiuti do Paraná (UTP) e Doutorado em Geografia pela Universidade Federal do Paraná
(UFPR). Professora do Departamento de Turismo da UFPR junto ao curso de Graduação em Turismo e ao
Programa de Mestrado em Turismo. E-mail: silvanasouza.tur@gmail.com
2 Artigo apresentado preliminarmente no formato de trabalho junto ao X Fórum Internacional de Turismo
do Iguassu, evento paralelo ao Festival de Turismo das Cataratas do Iguaçu, que ocorreu entre os dias 15 ,
16 e 17 de junho de 2016 na cidade de Foz do Iguaçu (Paraná, Brasil), selecionado entre os melhores
trabalhos na categoria artigos destaques e inserido como capítulo do livro Turismo e Megaeventos,
organizado por Francisco Antônio dos Anjos, Newton Paulo Angeli e Sara Joana Gadotti dos Anjos,
publicado pela Universidade do Vale do Itajaí em 2017 .
}

Turismo \& Sociedade (ISSN: 1983-5442). Curitiba, v. 10, n. 3, p. 1-25, setembro-dezembro de 2017. 
ABSTRACT - The impacts or effects caused by the tourism activity development process in the host communities are widely discussed in the tourism literature. In some cases are emphasized the negative impacts of tourism development such as the commodification of culture, caricaturing of the visited group and its traditional features and the demonstration effect. However, the tourism development also generates positive effects, such as cultural appreciation, preservation and rescue of cultural traits and heritage preservation. Thus, this paper aimed to "identify what would be the potential agents of socio-cultural changes in Brazilian indigenous communities" by the elaboration of a theoretical framework research, using as a basis Brazilian theses and dissertations about tourism involving indigenous, published between 1999 and 2012. It was found that tourism is only one of the potential socio-cultural change agents, and others are equally or even more shocking than this activity, such as government agencies, religious institutions and real estate sector actions.

Key words: Tourism; Indigenous communities; Socio-cultural impacts; Brazil. 


\section{INTRODUÇÃO}

O presente artigo, de caráter teórico-conceitual, está pautado nos impactos negativos e efeitos positivos resultantes do desenvolvimento da atividade turística, com ênfase no âmbito sociocultural. Questiona-se a relação entre o desenvolvimento do turismo e os impactos socioculturais ou se as alterações observadas em uma comunidade são, na verdade, resultado da dinamicidade cultural, de sua adaptação ao ambiente e às novas tecnologias, e, ainda, se a relutância em manter a identidade “cristalizada' não se constituiria em um obstáculo ao processo natural de evolução cultural (PEARCE, 2002). Outro aspecto trazido para o debate é a necessidade de discernir se os impactos são gerados por conta do turismo ou se o agente de mudança seria outro (ARCHER; COOPER; RUHANEN, 2005), bem como o grau de responsabilidade da atividade turística - e dos turistas - nessas mudanças, considerando também outras atividades econômicas ou outros atores sociais que as movimentam.

Desse modo, no presente artigo se teve como problemática: Quais seriam os agentes de potenciais mudanças socioculturais nas comunidades indígenas brasileiras? Para responder a tal questionamento o objetivo geral da pesquisa foi identificar quais seriam os agentes de potenciais mudanças socioculturais nas comunidades indígenas brasileiras. Para isso a pesquisa foi dividida em duas etapas. Na primeira, foi utilizado o método bibliográfico, por meio do qual se construiu o marco teórico a partir da literatura sobre os temas pertinentes aos impactos do desenvolvimento turístico, mais especificamente os socioculturais. Essa etapa foi desenvolvida como meio de aproximação às opiniões dos investigadores e para dar embasamento à pesquisa. Para isso, o debate centrou-se na relação entre visitantes e visitados e suas possíveis consequências, ou seja, os impactos resultantes dessa convivência.

A segunda etapa, por sua vez, esteve embasada na pesquisa documental, pautada no paradigma teórico-exploratório e descritivo. Nessa etapa, foram averiguadas, por meio da análise de conteúdo (utilizando-se da técnica de análise de avaliação), teses e dissertações brasileiras sobre turismo envolvendo comunidades indígenas, publicadas no período de 1999 a 2012 e listadas no Banco de Teses e Dissertações da Coordenação de Aperfeiçoamento de Pessoal de Nível Superior (CAPES, 2013; 2014), escolhido por ser um banco de dados confiável e que, por receber pesquisas diretamente dos 
Programas de Pós-Graduação do Brasil, agregaria um número preciso de pesquisas sobre o tema publicadas no país. O período considerado para a coleta dos dados compreendeu os anos de publicação a partir da pesquisa mais antiga e das mais atuais disponíveis, à época da consulta, no banco de dados supracitado. Após pesquisa e seleção, o corpus de análise ficou delimitado em 14 pesquisas.

Assim, abordam-se, primeiramente, questões pertinentes aos impactos no turismo, com foco nos aspectos socioculturais, apresentando alguns desses impactos, positivos ou (ditos) negativos, comumente abordados na literatura sobre o turismo. Em seguida tem-se os dados obtidos com a análise das teses e dissertações. Nele, apresentam-se os impactos socioculturais dentro de três perspectivas existentes visualizadas no corpus desta pesquisa: os impactos constatados nas pesquisas realizadas; os impactos que comumente foram elencados como resultados do desenvolvimento turístico, ou então que eram temidos pela comunidade receptora, mas que não eram reais no momento da pesquisa; e os impactos oriundos de outras atividades ou atores sociais que não o turismo e que, por essa razão, precisam ser diferenciados. Ao final, tem-se as considerações finais da pesquisa.

\section{EFEITOS, RESULTADOS, IMPACTOS: AS INTERFERÊNCIAS NOS ASPECTOS SOCIOCULTURAIS}

Os impactos podem ser entendidos como uma série de modificações (ambientais, econômicas, sociais ou culturais) ou eventos provocados pelo processo de desenvolvimento da atividade turística nas localidades receptoras (RUSCHMANN, 1997). Considerando que na presente pesquisa se focaliza os impactos socioculturais, faz-se importante que tal noção seja explicitamente definida. Com base em Dias (2008), pode-se afirmar que os impactos socioculturais (nas comunidades receptoras) são o resultado das relações sociais entre turistas e residentes que provoca mudanças sociais ou culturais na sociedade receptora. No entanto, cabe salientar que essa conceituação exclui os impactos causados nos próprios turistas. Para ilustrar, apresentam-se abaixo algumas evidencias da existência de impactos sociais e culturais (QUADRO 1). 
QUADRO 1 - EVIDÊNCIAS DA EXISTÊNCIA DE IMPACTOS SOCIAIS E CULTURAIS

\begin{tabular}{|c|c|c|c|}
\hline & \multirow[t]{2}{*}{ IMPACTOS SOCIAIS } & \multicolumn{2}{|c|}{ IMPACTOS CULTURAIS } \\
\hline & & Materiais & Imateriais \\
\hline EVIDÊNCIAS & $\begin{array}{l}\text { Ressentimento local resultante do choque } \\
\text { cultural; transformação da estrutura de } \\
\text { trabalho; saturação da infraestrutura, } \\
\text { gerando problemas quanto à terra, ao } \\
\text { emprego, ao transporte e à alta densidade } \\
\text { populacional; transformação de valores e } \\
\text { condutas morais (prostituição, uso de } \\
\text { drogas e aumento da criminalidade, etc.); } \\
\text { efeito demonstração }{ }^{3} \text {; problemas de } \\
\text { saúde (transmissão de enfermidades, } \\
\text { falta de saneamento e problemas } \\
\text { relacionados à precariedade/ausência de } \\
\text { infraestrutura básica); etnocentrismo; } \\
\text { excesso de padronização. }\end{array}$ & $\begin{array}{l}\text { Os artefatos } \\
\text { culturais perdem } \\
\text { seu significado } \\
\text { original, } \\
\text { transformando-se } \\
\text { em meros } \\
\text { produtos a serem } \\
\text { comercializados; } \\
\text { na arquitetura, } \\
\text { pode ocorrer uma } \\
\text { homogeneização, } \\
\text { com inserção de } \\
\text { padrões que não } \\
\text { condizem com o } \\
\text { estilo local. }\end{array}$ & $\begin{array}{l}\text { Expressões } \\
\text { culturais perdem } \\
\text { seu significado } \\
\text { original por causa } \\
\text { da intensa } \\
\text { comercialização; } \\
\text { assimilação dos } \\
\text { comportamentos } \\
\text { dos visitantes ou } \\
\text { mudança completa } \\
\text { no modo de vida } \\
\text { local. }\end{array}$ \\
\hline
\end{tabular}

Fonte: Adaptado de Dias (2008).

Dias (2008) considera, assim, que uma comunidade que apresenta forte identidade cultural e tradições consolidadas poderá resistir mais facilmente aos fluxos turísticos, absorvendo hábitos e costumes dos visitantes, mas sem perder a essência de seu modo de vida.

Para alguns estudiosos, o cerne dos impactos é a mercantilização da cultura. Greenwood (1989) destaca que tudo o que está à venda foi produzido por uma combinação de fatores de produção, ou seja, terra, mão de obra e capital. Além disso, segundo esse pesquisador, tudo aquilo que pode ser precificado, comprado e vendido pode ser considerado mercadoria, porém, quando os consumidores são atraídos por um determinado local graças à cultura, a questão da mercantilização se torna polêmica (GREENWOOD, 1989). Desde a perspectiva da mudança cultural, a mercantilização é tida como destruidora da cultura. No entanto, acredita-se, assim como defendido por Grünewald (1999), que, ao serem mercantilizadas, as práticas culturais adquirem novos significados para seus produtores, que se tornam veículos de autorrepresentação de sua identidade perante um público externo. Além disso, esse estudioso observa que, mesmo ocorrendo mudanças no significado dessas práticas, é possível que seus antigos significados permaneçam salientes para um público interno.

\footnotetext{
3 O efeito demonstração ocorre quando os hábitos de consumo das sociedades tradicionais são influenciados pelos dos turistas, ocasionando mudanças no comportamento, incluindo o acúmulo de bens materiais (RUSCHMANN, 1997; BURNS, 2002).
} 
A literatura sobre impactos, efeitos ou resultados dos fluxos turísticos nas comunidades, principalmente as denominadas 'tradicionais', conta com diversas vertentes de pensamento. Greenwood (1989) destacou haver dois enfoques elementares dentro dos estudos do turismo. O primeiro se concentrando na economia política; segundo esse enfoque, geram-se impactos substanciais, e a atividade turística promove a desagregação comunitária. No entanto, quanto ao segundo enfoque, antropológico, apregoa que as comunidades 'tradicionais' e estáticas se veem, de repente, lançadas sobre o cenário do capitalismo moderno. Nesse contexto, McKean (1989) propõe um continuum, sendo um dos extremos um "mundo turístico", no qual houve transformações completas nos âmbitos social e econômico, de modo que o destino resulta modelado conforme o sistema global; e no outro extremo um "mundo nativo", no qual não se produziram transformações, e a sociedade receptora segue exatamente como era anteriormente ao contato externo. Essas percepções, as atitudes e os interesses das comunidades pelo turismo estão longe de ser homogêneos (MALDONADO, 2009), por isso, a seguir, apresentam-se algumas perspectivas positivas e negativas quanto à relação entre visitantes e visitados.

\section{DECORRÊNCIAS POSITIVAS E NEGATIVAS DO DESENVOLVIMENTO TURÍSTICO}

O turismo contribui para uma considerável redistribuição espacial da capacidade de auferir renda, impactando positivamente sobre a economia dos destinos (ARCHER; COOPER; RUHANEN, 2005). As primeiras pesquisas sobre os impactos do turismo se concentravam justamente nos aspectos econômicos; porém, os benefícios econômicos foram contrapostos aos impactos ambientais e socioculturais, que não haviam sido mensurados anteriormente, conforme destacado pelos autores supracitados. Abaixo seguem alguns dos impactos negativos abordados na literatura sobre o turismo (QUADRO 2). 
QUADRO 2 - IMPACTOS NEGATIVOS DO DESENVOLVIMENTO TURISTICO

\begin{tabular}{|c|c|}
\hline AUTORES & IMPACTOS NEGATIVOS \\
\hline Talavera (2003) & $\begin{array}{l}\text { A cultura é objetivada e despersonalizada, tirada de seu contexto a fim de se obter } \\
\text { um produto apresentável como "autêntico"; caricaturização do grupo visitado e de } \\
\text { seus recursos tradicionais. }\end{array}$ \\
\hline $\begin{array}{l}\text { Barretto } \\
2005)\end{array}$ & $\begin{array}{l}\text { Ao ser transformado em produto, o legado cultural perde seu significado e a } \\
\text { cultura deixa de ser importante para si mesma e se torna importante } \\
\text { economicamente; desejo de modernização, descaracterizando as comunidades. }\end{array}$ \\
\hline McKean (1989) & $\begin{array}{l}\text { Homogeneização cultural, provocando a submissão das identidades étnicas a um } \\
\text { sistema industrial e tecnológico, com economia orientada para o consumo. }\end{array}$ \\
\hline Nash (1989) & Visitantes e visitados se veem como pessoas, mas também como objetos. \\
\hline Graburn (1989) & $\begin{array}{l}\text { Os visitados se transformam em objetos desumanizados; alteração na moralidade, } \\
\text { indicada por fatores como a prostituição, o abuso de drogas, o alcoolismo, a } \\
\text { criminalidade e os jogos de azar. }\end{array}$ \\
\hline Pearce (2002) & $\begin{array}{l}\text { Visitantes veem as cerimonias simbólicas e espirituais como "exóticas" ou } \\
\text { "lindas", banalizando o evento; Efeito demonstração. }\end{array}$ \\
\hline $\begin{array}{l}\text { Van den Berghe e } \\
\text { Keyes (1984) }\end{array}$ & $\begin{array}{l}\text { Os visitados se tornam menos tradicionais e mais parecidos com os turistas e, por } \\
\text { isso, menos interessantes (aos olhos do visitante); os turistas transformam os } \\
\text { visitados em "tourees", descaracterizando-os, ao mesmo tempo em que } \\
\text { "assaltam" a cultura anfitriã e sujeitam-na à modernização; se alteram os hábitos, } \\
\text { modo de consumo, valores, atitudes e linguagem, entre outros. }\end{array}$ \\
\hline Cohen (1985) & $\begin{array}{l}\text { Há cada vez mais uma "encenação" da cultura de modo a parecer algo autêntico } \\
\text { ao olhar do turista; }\end{array}$ \\
\hline $\begin{array}{l}\text { Ruschmann } \\
\text { (1997) }\end{array}$ & $\begin{array}{l}\text { Descaracterização do artesanato, que perde sua função original e passa a servir } \\
\text { como itens de decoração; vulgarização das manifestações tradicionais pela mídia, } \\
\text { que as mostra de modo simplista e estereotipado, e pela comunidade receptora, } \\
\text { que transforma as cerimônias em espetáculos; sentimento de inferioridade das } \\
\text { comunidades receptoras perante os turistas; banalização das crenças; efeito } \\
\text { demonstração. }\end{array}$ \\
\hline
\end{tabular}

Fonte: Elaboração própria (2015).

Com o quadro acima, pode-se perceber que as decorrências negativas no âmbito sociocultural parecem ter seu foco no modo como a cultura é vista e "tratada", como um recurso natural ou mercadoria sobre a qual os turistas têm direitos, assim como apontado por Greenwood (1989). O referido autor constata que sobram exemplos de expropriação e demolição cultural, geradas por conta de alguma variante do turismo; porém, ressalta que essa perspectiva proporciona uma visão parcial do processo.

Ademais, faz-se a ressalva de que estes não são necessariamente resultados advindos do contato entre culturas, mas são intensificados à medida que o turismo se desenvolve e aumenta a presença de forasteiros em um núcleo receptor (GRABURN, 1989; RUSCHMANN, 1997). Muitos desses efeitos são de natureza menos direta e nem todos são negativos (PEARCE, 2002). Burns (2002) ressalta que o turismo é uma força poderosa, mas, como fenômeno econômico e cultural, é um alvo fácil de culpabilização por quaisquer mudanças nas comunidades. Ademais, se por um lado indicam-se impactos negativos nas sociedades receptoras, alguns autores enaltecem que, por meio 
da atividade turística, podem ocorrer, também, efeitos positivos. Abaixo se apresentam alguns desses impactos positivos abordados na literatura (QUADRO 3).

\begin{tabular}{|c|c|}
\hline AUTORES & IMPACTOS POSITIVOS \\
\hline Esman (1984) & Proteção da cultura local. \\
\hline Greenwood (1989) & $\begin{array}{l}\text { Respostas criativas e positivas por parte dos visitados, em decorrência do } \\
\text { interesse que há por elementos como cultura, história e artesanato; } \\
\text { autovalorização da cultura local, orgulho das tradições e promoção da melhoria } \\
\text { da valia cultural. }\end{array}$ \\
\hline Talavera (2003) & $\begin{array}{l}\text { Compreensão entre visitantes e visitados e intercâmbio cultural, minimizando, } \\
\text { desse modo, conflitos e tensões; reconstrução das identidades locais, gerando } \\
\text { um processo de criação e recriação do sentido de pertencimento, lugar, passado, } \\
\text { cultura e posse. }\end{array}$ \\
\hline Maldonado (2009) & Valorização do acervo patrimonial comunitário. \\
\hline Brasil (2006) & $\begin{array}{l}\text { Valorização da identidade cultural e resgate cultural; preservação do patrimônio } \\
\text { histórico e cultural; intercâmbio entre culturas, promovendo a compreensão, o } \\
\text { conhecimento e o respeito à diversidade. }\end{array}$ \\
\hline Boissevan (2005) & $\begin{array}{l}\text { Os visitados se dão conta do quão diferentes são e torna-se motivo de orgulho a } \\
\text { escolha dos forasteiros por visitar sua comunidade e vivenciar seus costumes; } \\
\text { comunidades percebem as especificidades de sua própria cultura e descobrem } \\
\text { novas dimensões de sua identidade, o que fomenta a preservação do artesanato e } \\
\text { até mesmo o ressurgimento de rituais já extintos. }\end{array}$ \\
\hline Dias (2008) & $\begin{array}{l}\text { A cultura local, em vários de seus aspectos, sobrevive ou é renovada pelo } \\
\text { interesse despertado pelos turistas. }\end{array}$ \\
\hline Cohen (1985) & $\begin{array}{l}\text { A comoditização da cultura facilita a preservação das tradições culturais que } \\
\text { talvez se extinguissem se não fossem inseridas no turismo. }\end{array}$ \\
\hline MacCannell (1984) & Recriação, preservação e manutenção dos atributos étnicos e culturais. \\
\hline Ruschmann (1997) & $\begin{array}{l}\text { Valorização do artesanato; valorização da herança cultural, como as cerimônias } \\
\text { religiosas; fortalecimento do orgulho étnico; valorização e preservação do } \\
\text { patrimônio. }\end{array}$ \\
\hline
\end{tabular}

Fonte: Elaboração própria (2015).

Entende-se que os impactos destacados acima, são um retrato da dinamicidade das culturas, que mudam em respostas ao ambiente e à tecnologia, e, na tentativa de manter a identidade cristalizada, impede-se o processo natural de mudança cultural, assim como defendido por Barretto (2000) e Pearce (2002). Salienta-se que é preciso compreender que existem diferentes perfis de turistas e modalidades de experiências turísticas e, por isso, as interferências decorrentes do desenvolvimento turístico tendem a ser diferentes em cada destino (PEARCE, 2002). Assim, conforme ressalta esse autor, faz-se necessário analisar se as mudanças estão ocorrendo por conta do turismo ou por pressão das circunstâncias e da dinâmica interna da sociedade visitada. Sendo externos à comunidade, é importante discernir se os impactos são gerados por conta do turismo ou se o agente de mudança é outro (ARCHER; COOPER; RUHANEN, 2005). Torna-se 
difícil a distinção do que são impactos oriundos das relações no turismo e o que são parte do processo geral de modernização (PEARCE, 2002).

Assim, faz-se necessário examinar alguns pressupostos sobre os impactos sociais e culturais ocasionados pelo desenvolvimento turístico que prevalecem na literatura do turismo, conforme Cohen (1985). O referido pesquisador esclarece que, ao invés de assumir que há impactos negativos na autenticidade com a mercantilização da cultura, esse "impacto" deve ser submetido a um exame empírico, por meio do qual se poderia compreender os aspectos culturais preservados, os que emergem com o turismo e os que foram ou estão sendo destruídos por impactos advindos do desenvolvimento turístico e do contato entre visitantes e visitados.

\section{OS IMPACTOS SOCIOCULTURAIS ORIUNDOS DO DESENVOLVIMENTO TURÍSTICO}

Nesta seção, são abordados os impactos socioculturais, relacionados ao turismo ou não, mais sobressalientes nas teses e dissertações estudadas. O conteúdo está desdobrado em subseções que tratam dos impactos socioculturais reais do desenvolvimento turístico nas comunidades estudadas; o que se infere sobre o turismo; e os impactos oriundos de outras atividades.

\subsection{OS IMPACTOS SOCIOCULTURAIS REAIS NAS COMUNIDADES ESTUDADAS}

Ao se abordarem os impactos socioculturais oriundos, teoricamente, do desenvolvimento do turismo, é preciso ressaltar que, em todas as pesquisas analisadas, percebeu-se certa imparcialidade - por parte dos pesquisadores - quanto ao tema. Entende-se aqui a imparcialidade não como sinônimo de despreocupação; ao contrário, todos os pesquisadores se mostraram cientes das modificações que ocorrem no contato. Porém, ressalta-se que tais mudanças são parte de um processo gradativo e constante de alterações culturais. O que ocorre, no turismo, é, talvez, uma aceleração dessas mudanças, e, geralmente, elas preocupam a comunidade receptora quando se trata de 
comportamento desrespeitoso ou da inserção de valores que não condizem com os valores da comunidade, como é o caso do uso de drogas - por parte de alguns turistas que propõem trocar peças artesanais por drogas - na aldeia de Barra Velha, Porto Seguro, e na Terra Indígena (TI) da Coroa Vermelha, Santa Cruz de Cabrália, na Bahia , fato que desagradava os indígenas (GRÜNEWALD, 1999).

Outra questão que deve ser ressaltada é o fato de que, em todas as comunidades pesquisadas, a principal atividade turística mencionada foi a de comercialização de artesanato, e essa se posicionando como uma importante fonte de renda para as comunidades. No caso dos Pataxó, por exemplo, o artesanato estava sendo a base da economia (GRÜNEWALD, 1999), sendo o fator definidor da maior ou menor prosperidade das famílias (NEVES, 2012).

$\mathrm{O}$ artesanato foi uma das expressões culturais mais abordadas nas pesquisas, e também se debateu sobre sua "autenticidade", uma vez que as comunidades alteraram suas peças para torná-las mais agradáveis aos olhos dos turistas. No caso dos Pataxó, os trabalhos artesanais que eram comercializados quando da pesquisa de Grünewald (1999) foram criados não havia muito tempo e se tratavam de trabalhos mais decorativos, ou seja, não tinham mais uma função utilitária para as comunidades. Nunes (2006) também aborda esse aspecto ao analisar a aldeia Puiwa Poho, em Feliz Natal, Mato Grosso, onde o artesanato estava sendo produzido com intenções mercadológicas e as peças se tornaram mais parecidas entre si, deixaram de ter função como utensílios domésticos e objetos de lutas e passaram a ser suvenires.

Sobre esse tema, Lac (2005) destaca que se discute a produção em massa do artesanato indígena, o pagamento irrisório, a troca desigual de produtos artesanais que demandam tempo e esforço, a introdução de materiais diferentes, a confecção de objetos cerimoniais, a escassez de matéria prima, entre outras problemáticas em torno da produção artesanal. No entanto, essa pesquisadora salienta que, apesar desses problemas, foi o artesanato mercantil que salvou a prática artesanal em diversas comunidades indígenas e, sobretudo, reforçou a identidade étnica desses povos, inclusive na TI de Iraí, em Iraí, Rio Grande do Sul.

Além disso, tem-se o fato de que o artesanato produzido pelos indígenas em dada comunidade estava sendo consumido em lugares distantes, tornando possível a aquisição de objetos simbólicos antes disponíveis apenas em museus (SANTOS, 2010). 
Por isso, além de ser uma forma de marketing turístico, era também marketing cultural. Ademais, o autor citado expõe que as artes contribuem para o fortalecimento da identidade étnica, pois os indígenas estabelecem uma distinção entre objetos que são parte de sua tradição e os que são exógenos.

O artesanato é utilizado como expressão cultural, para reforçar a existência e a indianidade das comunidades, como estava ocorrendo com os Pataxó (GRÜNEWALD, 1999; NEVES, 2012) e com os Kaingang de Iraí, que tinham seu território remodelado e as tradições valorizadas com a venda de artesanato (LAC, 2005). Neves (2012) relata que, no Centro de Artesanato, a sobrevivência familiar e individual - geração de renda a sobrevivência coletiva e a manutenção de um discurso étnico-identitário estavam em jogo. Foi adotada, inclusive, a padronização das peças. Também, segundo constatado por esse investigador, era por meio do comércio do artesanato que os indígenas conversavam com os visitantes e tinham a possibilidade de contar sua história e, assim, divulgar sua cultura.

Divulgação da cultura foi, aliás, um termo mencionado diversas vezes nas pesquisas consultadas. Os Terena da aldeia Marçal de Souza, em Campo Grande, Mato Grosso do Sul, esperavam que, com o turismo, as pessoas se interessariam em conhecer sua cultura e acabariam por divulgá-la (LACERDA, 2004). Segundo Nunes (2006), uma proposta do Centro de Cultura Indígena na RI de Dourados, em Dourados, Mato Grosso do Sul, que acabou não sendo realizada, poderia ser uma estratégia de divulgação da cultura e aumento da demanda de turistas étnicos; porém, isso não foi realizado, com a interrupção do projeto.

Além disso, a quebra de paradigmas ocorre, e, por mais que, às vezes, decepciona os turistas - por não encontrarem o "índio autêntico" -, outras vezes, é por meio do contato que os visitantes conhecem o modo de vida, a cultura e os problemas existentes nessas comunidades. Lac (2005) relata que a comunidade Kaingang da TI de Iraí via o turismo, inserido em um processo de resgate cultural, como uma estratégia de conscientização dos não indígenas quanto às necessidades dos indígenas, principalmente no que diz respeito às problemáticas territoriais.

Foram abordados nas pesquisas consultadas outros impactos, alguns vistos como positivos e outros negativos: guias de turismo que não consultavam a comunidade visitada, pagamento - quando havia - em bebida alcoólica, fumo ou comida, nas 
comunidades do Alto Rio Negro, no Amazonas (FARIA, 2008); a tentativa - fracassada - de mercantilizar a cultura indígena na RI de Dourados; a espetacularização e a mudança de significado das técnicas artesanais, como pesca, preparo do beiju, produção de sal de aguapé e a mercantilização do ritual Jawari na aldeia Puiwa Poho (ainda que visto como autêntico pelos turistas) (NUNES, 2006). Neste último caso, o autor ressalta que o ritual continuava tendo seu significado preservado, embora se apresentasse aos turistas uma encenação, que não necessariamente precisa ter o significado original, assim como estava ocorrendo com o ritual da tucandeira realizado pelos Sateré-Mawé, da comunidade Sahu-Apé, em Iranduba, Amazonas. Nesse caso, os turistas podem acompanhar o ritual de fato ou, o que é mais comum, a encenação do ritual - ainda que os turistas não saibam que se trata de uma simulação (SANTOS, 2010).

Oliveira (2006), no entanto, defendeu que a descaracterização é uma concepção mumificada e descontextualizada da realidade dos indígenas na sociedade contemporânea. Entende-se, assim, que os impactos oriundos do desenvolvimento turístico se revelam quando os turistas buscam a universalização da cultura indígena. Esse investigador ressaltou que os impactos do turismo em áreas indígenas não poderiam ser analisados desde uma perspectiva redutora, elegendo um grupo social mais forte (os turistas) e um grupo social mais fraco (os indígenas). A partir desse ponto de vista, defende-se que os impactos relacionados ao turismo em comunidades indígenas devem ser analisados a partir de outra perspectiva. Pelos relatos dos pesquisadores, pôde-se perceber que, com raras exceções, as comunidades gostavam de receber turistas ou eram saudosistas em relação ao tempo em que os recebiam.

Também há de se levar em consideração que as comunidades não são homogêneas, e, portanto, as experiências turísticas assumem, às vezes, características positivas. Além disso, o turismo era comumente visto como uma oportunidade de dar voz aos povos indígenas ou de estes reafirmarem seus territórios, como ocorreu com os Jenipapo-Kanindé, em Aquiraz, Ceará, que implantaram o turismo comunitário, que contribuiu para a valorização territorial e cultural, a afirmação étnica, a criatividade cultural, a participação ativa de jovens e adultos, bem como a exploração sustentável dos recursos naturais e culturais (LUSTOSA, 2012), além do fator econômico, amplamente abordado. Esse fator parece ser, inclusive, de menor importância quando a experiência é positiva para a comunidade receptora. Também significa uma perspectiva 
econômica para os jovens Pataxó, como no serviço de guiamento de visitantes (NEVES, 2012); reativação de práticas culturais, como os cavaleiros Kadiwéu, em Porto Murtinho, Mato Grosso do Sul (JESUS, 2012) e o Pajé Pataxó - ainda que este fosse visto como um "pajé turístico" (NEVES, 2012); aumento na qualidade de vida individual; diminuição da probabilidade de êxodo; melhorias na autoestima e interesse dos jovens pela língua materna e por técnicas de artesanato (BRANDÃO, 2012). Numa análise mais ampla, pode-se dizer que a participação comunitária poderia minimizar ou anular riscos de impactos (FARIA, 2008; JESUS, 2012).

No caso da TI São Marcos, em Pacaraima, Roraima, Brandão (2012) constatou que a atividade turística já ocorria na comunidade havia mais de dez anos e não haviam sido feitos estudos de impacto de qualquer natureza. Porém, a maioria dos indígenas entrevistados afirmaram que não houve aumento de reclamações contra os turistas, os moradores não se sentiam intimidados com a presença deles, o turismo não tinha contribuído para a existência de conflitos étnicos e também não foram afetadas as tradições culturais. No caso dos Kaingang de Iraí, havia certa indiferença frente à movimentação turística, e tal comportamento partia do princípio de que a vida é, com pequenas variações, a mesma, com ou sem turistas (LAC, 2005).

Cada uma dessas comunidades vivenciava a atividade turística de um modo. Ademais, é necessário levar em consideração a autonomia desses povos e sua capacidade de gestão e controle do turismo. No caso da TI de Mangueirinha, localizada nos municípios de Mangueirinha, Coronel Vivida e Chopinzinho, Paraná, por exemplo, um dos caciques relatou a Baggio (2007) que eles conheciam seus limites e que os turistas tomavam ciência das regras que deviam respeitar dentro da TI; ademais, os indígenas sabiam o perfil que poderiam acolher nas aldeias e o que poderiam tirar de positivo e de negativo da experiência com os visitantes. Por fim, salienta-se que as comunidades, assim como destacado por Grünewald (1999), não pareceram estar sendo destruídas, mas sim transformadas. Essa transformação, em parte, diz respeito ao turismo, mas ressalve-se que não somente a atividade turística contribui para tais modificações. 


\subsection{O QUE SE INFERE SOBRE O TURISMO}

Nesta pesquisa, distinguiu-se o que são impactos reais oriundos da atividade turística, acima apresentados, do que são impactos comumente apresentados como resultados do desenvolvimento turístico, mas que não necessariamente ocorrem. No corpus de análise, esses impactos prováveis foram apontados, em maior número, pelos próprios investigadores. No entanto, por vezes, os entrevistados apontaram algumas preocupações referentes ao turismo nas comunidades estudadas. Os motivos dessas inquietações são apresentados na sequência.

Lacerda (2004) considerou, em sua pesquisa, que o turismo e a venda de artesanato realizada pelos Terena poderiam incentivar o resgate de peças não mais produzidas, incitando a continuidade da tradição. Além disso, os indígenas esperavam que o turismo possibilitasse um aumento de postos de trabalho, renda e que, por meio dele, os visitantes conhecessem a cultura Terena. No entanto, pontua-se a preocupação de que, à medida que eles ganhassem dinheiro, houvesse alteração na sua cultura. Ademais, o risco de serem vistos como exóticos poderia reforçar os preconceitos. Lac (2005), por sua vez, apontou que, à medida que o número de turistas aumentava, os nativos se tornavam tourees e as comunidades tornavam-se pseudocomunidades que se sobrepunham às comunidades étnicas.

Nunes (2006) relata que se vivia uma "moda indígena", por meio da qual os indígenas não eram mais perseguidos, mas sim admirados. No entanto, os indígenas que não atendessem às expectativas do turismo como "índios autênticos" não seriam aceitos no mundo contemporâneo.

Faria (2008), por sua vez, destacou o fato de que os debates acerca do turismo em áreas indígenas giravam em torno da presença do turista, que poderia provocar a descaracterização cultural, perturbar o cotidiano da comunidade e promover a mercantilização da cultura, além de trazer problemas como doenças, biopirataria, violação do patrimônio, entre outros. No entanto, assim como salientado por essa investigadora, os mesmos atores que condenavam a atividade ignoravam que ela já estivesse ocorrendo, e de forma clandestina. Portanto, uma das questões essenciais para a minimização dos impactos socioculturais seria a regulamentação legal do turismo em áreas indígenas. 
Os indígenas do Alto Rio Negro, estudados por Faria (2008), relataram seus medos e suas crenças quanto aos impactos ocasionados no desenvolvimento do turismo, entre os quais se destacaram: invasão e apropriação do patrimônio; intimidação dos habitantes; desrespeito aos costumes; risco de descaracterização cultural; uso insustentável dos recursos materiais para confecção de artesanato; individualismo e desunião interna; risco de contágio de doenças, entre outros. Além disso, relatou-se o medo de que os visitantes fossem traficantes, guerrilheiros ou espiões, demonstrando o temor de que pessoas mal-intencionadas usassem o turismo como forma de entrar no território indígena.

Por outro lado, visualizavam as vantagens do ecoturismo: proteção do território; geração de emprego e renda; melhoria das condições de vida; valorização dos costumes, entre outras. Para esses indígenas, o desenvolvimento do turismo deveria ser, ainda, organizado e participativo, realizado pela própria comunidade. Apesar de as respostas dadas pelos indígenas não serem padronizadas, eles se mostraram cientes do que era necessário para implantar o turismo - nesse caso, ecoturismo - visando a impactos mínimos, o que, provavelmente, foi resultado das oficinas de capacitação de que participaram.

Leandro (2011), por sua vez, elencou os prováveis impactos socioculturais, não diferindo muito do que foi exposto por Faria (2008). Entre os impactos, ressaltaram-se: perda da autenticidade das manifestações; transformação da identidade cultural por conta da influência de outras culturas; degradação patrimonial; desqualificação profissional; e aumento de problemas sociais, como o uso de drogas e a criminalidade. Assim como no caso de Faria (2008), Leandro (2011) estudou uma comunidade que ainda não havia implantado a atividade turística (os Paiter-Surui da TI Sete de Setembro, localizada nos municípios de Cacoal e Espigão d'Oeste, Rondônia, e Rondolândia, no Mato Grosso); portanto, buscava desenvolver um plano de gestão visando, entre outras coisas, a minimizar impactos. Segundo relato desse investigador, para o líder dos Paiter-Surui, o ecoturismo viria a ser, entre outras coisas, um gerador de renda e um meio de valorização cultural. Entende-se que ambas as iniciativas são importantes, nesse caso, pois previnem eventuais impactos.

Ramos (2008), que estudou os Tupinambá do Distrito de Olivença, em Ilhéus, Bahia, cita que o florescimento ou a intensificação cultural pós-contato se tornaram 
"clichês antropológicos". Nesse sentido, para Jesus (2012), o contato estava promovendo a espetacularização e a mercantilização da cultura, entre outros impactos; e a produção, a reprodução e a reinvenção da tradição eram formas de alcançar essa mercantilização. Esse mesmo investigador ressaltou, no entanto, que as culturas indígenas sempre sofreram e continuariam sofrendo interferências, de ordem econômica, social, espacial, territorial, ambiental e cultural. No entanto, salienta-se que essas interferências nem sempre estão relacionadas à atividade turística.

\subsection{OS IMPACTOS SOCIOCULTURAIS NÃO RELACIONADOS AO TURISMO}

Constatou-se, com a pesquisa, que nem sempre os impactos estavam relacionados à atividade turística. De modo mais expressivo, tendo-se o impacto ocasionado pelo poder público, em especial os órgãos responsáveis pelos povos indígenas - o extinto Serviço de Proteção do Índio (SPI) e, depois, a Fundação Nacional do Índio (Funai). Um dos entrevistados por Baggio (2007), funcionário da Funai, afirmou que o turismo poderia contribuir para interferências na cultura, mas, por outro lado, essa instituição buscava, justamente, a integração dos indígenas e sua aculturação. Já Grünewald (1999) constatou que, entre as tradições geradas pelos Pataxó, a língua e o uso de nomes indígenas foram, na verdade, quase impostos pela Funai, para fossem reconhecidos como indígenas. Também houve uma orientação, por parte do extinto SPI, para que os Pataxó dançassem o Toré, inclusive como requisito para o reconhecimento de suas terras.

Lac (2005) também constatou que o Governo Federal exigia que os indígenas mantivessem sua distinção cultural, a fim de justificar as políticas diferenciadas, por vezes, transformando os indígenas em tourees. Pode-se afirmar que, ao contrário do que ocorre no turismo onde os indígenas expõem seus traços culturais, no caso da imposição feita pelo poder público, os indígenas precisavam provar que eram indígenas, estimulando práticas simuladas. Nesse sentido, Grünewald (1999) expõe que o processo de mudança cultural estava sendo um resultado da interação entre os indígenas, a sociedade e as autoridades.

Outro agente de mudanças socioculturais são os meios de comunicação, em especial a televisão, conforme relatado pelo mesmo entrevistado. Observou-se, na pesquisa, serem raras as casas que não possuíam televisão na TI Mangueirinha, e as que 
não a possuíam, à época da pesquisa, tinham rádio. A cultura exógena é apresentada nas emissoras de televisão a todo o tempo. Considera-se, desse modo, que o contato pessoal com não indígenas não seja tão alarmante. Ademais, pode-se agregar a esses meios um terceiro, a internet.

Foi identificado, ainda, um terceiro elemento causador de mudanças socioculturais nas comunidades pesquisadas: as instituições religiosas. Na TI de Iraí, a presença de igrejas, católicas e evangélicas, era expressiva. No entanto, nesse caso, os Kaingang não viam a religião como uma interferência negativa; ao contrário, para alguns, ela poderia ser mediadora no contato com não indígenas. No caso dos Pataxó da Coroa Vermelha, o pajé - ainda que fosse considerado um "pajé turístico" - se recusou a fazer pajelança - rituais místicos realizados pelos pajés -, pois passou a ser membro de uma igreja evangélica, fazendo apenas orações cristãs (NEVES, 2012). Já na RI Kadiwéu, as igrejas evangélicas desestimulavam as manifestações culturais ritualísticas, que se encontravam praticamente em desuso, pois incitavam a ideia do pecado (JESUS, 2012). Grünewald (1999), por sua vez, constatou, por meio de uma entrevista com um missionário, que este acreditava que o catolicismo havia "feito um estrago" na aldeia de Barra Velha. Assim, percebe-se que as igrejas ou as religiões adotadas podem também promover mudanças socioculturais.

$\mathrm{Na}$ pesquisa de Lustosa (2012), por seu turno, constatou-se que o litoral cearense, ocupado pelos Jenipapo-Kanindé e pelos Tremembé, no Ceará, estava sendo alvo de diferentes projetos, como integração do litoral por meio de rodovias, construção de condomínios residenciais, construção de portos, parques de energia eólica, usina siderúrgica e termelétrica, agronegócio, entre outros. Na visão da pesquisadora, essa infraestrutura valorizava os territórios indígenas, mas o discurso de progresso e desenvolvimento econômico no qual estavam englobados promovia mudanças drásticas na vida e na cultura das comunidades, que eram, aos poucos, recrutadas como mão de obra nos empreendimentos.

Por fim, constatou-se que o Exército Brasileiro também gerou alterações. Em São Gabriel da Cachoeira, Amazonas, com a instalação da $2^{\mathrm{a}}$ Brigada de Infantaria de Selva e consequente vinda de aproximadamente 2 mil militares, a partir de 2005, houve um crescimento desordenado da cidade com ocupação de lugares impróprios (FARIA, 2008). Com isso, segundo a pesquisadora, ocorreu a poluição dos igarapés e das praias, 
além de terem surgido ou se agravado problemas relacionados à ausência de saneamento básico, como inexistência de esgoto sanitário, estação e tratamento de água e esgoto, aterro sanitário, entre outros. Ademais, as construções de todos os tipos e em diversos lugares e a proliferação de locais de lazer sem estudos de impactos, geraram impactos sociais, como desemprego, alcoolismo, falta de moradia, moradia sem condições mínimas de habitação (FARIA, 2008). Essas condições afetaram não apenas os militares que foram viver no município, mas também a população local.

Conforme os relatos postos acima, considerou-se haver diversos agentes de mudanças socioculturais em constante relação com as comunidades indígenas. Por isso, refuta-se a ideia do turismo como "causador de todos os males" não condizendo com a realidade observada nas comunidades indígenas. Como apontado por Jesus (2012), a própria modernidade exige adaptações nos hábitos e nos costumes tradicionais, e, com essa nova realidade, intensificam-se os conflitos socioculturais, como miséria, suicídio, dependência química, entre outros. Desse modo, além dos agentes de mudanças, faz-se necessário abordar as alterações que ocorrem de modo gradativo como parte da dinâmica sociocultural local. O primeiro exemplo a ser destacado é o das alterações sofridas com o contato com outros grupos indígenas, amplamente abordado por Grünewald (1999) e Neves (2012), conforme exposto no tópico anterior.

Oliveira (2006) destacou que, durante as viagens para outros territórios indígenas e cidades (ou seja, ao praticarem o turismo), os indígenas mantinham contatos, ensinavam e adquiriam experiências novas, e, ao retornarem para suas comunidades, essas experiências eram, por vezes, discutidas, podendo promover mudanças socioculturais significativas, como a incorporação de traços de outras etnias ou a simples implantação de melhorias na infraestrutura.

Em outros casos, os traços culturais são abandonados ou passam a ser menos expressados. Na TI Mangueirinha, por exemplo, as danças estavam restritas a ocasiões em que havia audiência externa ou eventos comemorativos; o artesanato não tinha mais utilidade doméstica; a gastronomia tradicional sofreu modificações com a inserção de elementos antes não utilizados; a reorganização da aldeia, com construções realizadas pelo poder público, passou a ser incorporada pela comunidade, conforme relato de Baggio (2007). No entanto, o pesquisador afirmou que, mesmo ressignificados, esses aspectos culturais tinham uma razão de ser para as comunidades. Os indígenas apenas 
passaram a dar menos importância aos elementos tradicionais que não lhes faziam mais sentido, como a caça, por exemplo.

No caso dos Terena, conforme expresso por Lacerda (2004), não havia tanta semelhança nos modos e nos costumes vigentes com aqueles vividos por seus antepassados, a não ser pelo envolvimento familiar e comunitário, pela língua materna ensinada na escola e por algumas manifestações culturais apresentadas somente nas festividades do Dia do Índio, como a Dança do Bate-pau, que representa o episódio da guerra do Paraguai, na qual os Terena tiveram grande importância na defesa brasileira. Para o pesquisador, essas mudanças poderiam ser resultado do esforço dos Terena pela própria sobrevivência.

Os Kadiwéu, estudados por Jesus (2012), por sua vez, tiveram seus hábitos e costumes transformados, entre outros motivos, pela evolução tecnológica e macroeconômica. Algumas modificações observadas foram: a língua materna não ser mais usada pelos jovens, entre outras razões, pelo fato de haver casamentos com pessoas externas à RI Kadiwéu; o ensino nas escolas não ser totalmente no idioma indígena; e o material didático ser redigido em português. A indumentária mostrava-se totalmente influenciada pela moda não indígena. As pinturas corporais e faciais, associadas aos rituais e cerimonias tradicionais, não eram mais usadas. As cavalgadas os Kadiwéu são conhecidos como "índios cavaleiros", devido à participação em guerras intertribais e do Paraguai - aparentemente não ocorriam mais, ainda que fosse motivo de orgulho para esses indígenas e que houvesse criação de cavalos da RI. As moradias também foram modificadas, sendo de alvenaria, e as edificações tradicionais, se encontravam abandonadas (JESUS, 2012).

As moradias dos Sateré-Mawé também foram sendo modificadas; porém, esses indígenas afirmaram que suas casas estavam baseadas nas tradicionais, conforme Santos (2010). Esse investigador destacou a problemática em relação a isso, sendo a casa um mundo particular em que todas as coisas que "não são do índio" poderiam ser desfrutadas. Segundo o autor, trata-se de um espaço contra a desqualificação da etnicidade e onde os indígenas não precisam estar constantemente provando sua indianidade.

Aparentemente, essas mudanças não são bem vistas na atividade turística. Nunes (2006) verificou na Reserva Indígena (RI) de Dourados que a pobreza local não 
satisfazia o imaginário do turista e que, ao se identificarem mais com o modo de vida ocidental, urbano e excludente, os indígenas tornavam-se menos atrativos aos olhos dos visitantes. No entanto, segundo esse pesquisador, no caso dessa RI, apesar de não disporem de matas ou rios, os indígenas ainda resguardavam suas tradições. Considerase, com isso, que as modificações substanciais no modo de vida e nos aspectos socioculturais dos indígenas desagradam ou tornam a comunidade menos atrativa para os visitantes, que, ao mesmo tempo, não se preocupam em entender tais alterações e a própria dinamicidade cultural.

Por fim, destaca-se a proximidade com centros urbanos como um fator de modificação, e, dentro desse contexto, o êxodo de jovens em busca de emprego e melhores condições de vida, o que fragiliza a coesão cultural, como ocorreu na TI São Marcos (BRANDÃO, 2012). Os jovens parecem ser os principais modificadores socioculturais. Quanto a isso, Lac (2005) constatou que, na visão de um dos caciques da TI de Iraí, o que se esperava era apenas que eles (os jovens) não perdessem sua cultura e seus costumes, que não se esquecessem de sua indianidade.

\section{CONSIDERAÇÕES FINAIS}

Verificou-se que os impactos são, por vezes, atribuídos exclusivamente ao desenvolvimento da atividade turística. Para alguns estudiosos, o cerne dos impactos é a mercantilização da cultura. Essa mercantilização e o próprio contato entre diferentes culturas ocasionariam impactos socioculturais negativos, como despersonalização e espetacularização da cultura, modernização cultural e abandono de tradições, destruição do exotismo, aculturação e, inclusive, alteração na moralidade (prostituição, abuso de drogas, alcoolismo, criminalidade, entre outros). No entanto, é preciso se ater ao fato de que o desenvolvimento da atividade turística, com destaque aos "novos turismos", também gera impactos positivos, tais como proteção da cultura de um local, compreensão e intercâmbio cultural, valorização do acervo patrimonial comunitário, fortalecimento da etnicidade e orgulho cultural, intensificação cultural, enriquecimento da cultura tradicional, reconstrução das identidades locais, entre outros. 
Outras duas questões devem ser levadas em consideração. A primeira é que, conforme pôde ser percebido com a análise bibliográfica, os impactos negativos não são, necessariamente, resultados advindos do contato entre culturas. Eles se intensificam na medida em que o turismo se desenvolve e aumenta a presença de forasteiros numa comunidade receptora (GRABURN, 1989; RUSCHMANN, 1997). Assim, quanto mais desenvolvido turisticamente for um destino, maior a probabilidade de que os impactos negativos se sobressaiam, o que ainda não é uma realidade nas comunidades indígenas do Brasil, uma vez que o turismo realizado nesses espaços é incipiente, não sendo caracterizado como massificado.

A segunda questão que pôde ser percebida com a pesquisa é que, assim como destacou Burns (2002), o turismo como um fenômeno econômico e cultural é alvo fácil para receber a "culpa" por quaisquer mudanças nas comunidades, principalmente as de caráter socioculturais. Porém, não apenas turistas e atores do turismo são agentes de mudanças; há outros que podem contribuir para que ocorram alterações, como comerciantes, educadores e agentes do governo (NASH, 1989). Com a pesquisa constatou-se que ocorriam mudanças socioculturais por razão do desenvolvimento turístico, nas comunidades estudadas; no entanto, outros agentes eram tão impactantes quanto essa atividade, sendo os principais agentes de mudanças o poder público, a mídia e os grandes empreendimentos, com ênfase para o setor imobiliário. Apesar de perceber-se uma inclinação, na literatura, para os impactos ocasionados pelo desenvolvimento turístico, compreende-se ser necessário o desenvolvimento de pesquisas, no turismo, que contestem a ideia de que as mudanças são geradas unicamente, ou principalmente, por conta da atividade turística. Com a pesquisa, tomouse conhecimento de alguns agentes de mudança que não foram sequer cogitados, como é o caso das igrejas inseridas nas áreas indígenas, que ocasionam mudanças, principalmente no que diz respeito às cerimonias ritualistas e à pajelança.

Verificou-se, por fim, que as comunidades estudadas, tendo diferentes experiências no turismo, não poderiam ser categorizadas quanto aos impactos do turismo. Em alguns casos, o turismo surgiu como um modo de auferir renda; em outros, além disso, como um meio de divulgação cultural e de reafirmação territorial; havendo ainda os casos em que o turismo estava inserido em um projeto "de cima para baixo"; também existindo comunidades que ainda planejavam a atividade, entre outros casos. 
Por fim, considera-se que todas essas diferenças devem ser levadas em consideração no planejamento turístico e principalmente na política indigenista para o turismo.

\section{REFERÊNCIAS}

ARCHER, B.; COOPER, C.; RUHANEN, L. The positive and negative impacts of tourism. In: THEOBALD, W. F. (Ed.). Global Tourism. 3 ed. Burlington (EUA): Elsevier Science, 2005. p. 79-102.

BAGGIO, A. J. Ecoturismo: alternativa sustentável de valorização do patrimônio natural e cultural da Terra Indígena Mangueirinha, PR. 178 p. Dissertação (Mestrado em Ciências Sociais Aplicadas), Universidade Estadual de Ponta Grossa, Ponta Grossa, 2007. Disponível em:

<http://www.dominiopublico.gov.br/download/texto/cp043493.pdf>. Acesso em: 04/07/2015.

BARRETTO, M. Turismo e legado cultural. 4. ed. Campinas, SP: Papirus, 2000. Coleção Turismo.

Turismo étnico y tradiciones inventadas. In: TALAVERA, A. S.; PRATS CANALS, L. (Coord.). El encuentro del turismo con el patrimonio cultural: concepciones teóricas y modelos de aplicación. Sevilla (ESP). FAAEE- Fundación El Monte, p. 39-56, 2005. Disponível em:

<http://sgpwe.izt.uam.mx/files/users/uami/mcheca/GEOPATRIMONIO/LECTURA3H. pdf>. Acesso em: 10/05/2015.

BOISSEVAN, J. Rituales ocultos. Protegiendo la cultura de la mirada turística. (Trad. Ramón Hernandez Armas). Pasos - Revista de Turismo y Patrimonio Cultural, v. 3, n. 2, p. 217-228, 2005. Disponível em: <http://www.pasosonline.org/Publicados/3205/PS010205.pdf >. Acesso em: 25/05/2015.

BRANDÃO, C. N. Turismo em Terras Indígenas como fator de desenvolvimento local sustentável: estudo de caso nas comunidades indígenas de Roraima. $158 \mathrm{p}$. Dissertação (Mestrado em Administração de Empresas), Fundação Getúlio Vargas/SP, São Paulo, 2012. Disponível em:

<http://bibliotecadigital.fgv.br/dspace/bitstream/handle/10438/10293/Disserta\%C3\%A7 \%C3\%A3o_Mestrado_Final_Version_2012.pdf?sequence=1>. Acesso em: 04/07/2015.

BRASIL. Ministério do Turismo. Segmentação do turismo: marcos conceituais. Brasília: Ministério do Turismo, 2006. Disponível em: <http://www.turismo.gov.br/export/sites/default/turismo/o_ministerio/publicacoes/down loads_publicacoes/Marcos_Conceituais.pdf>. Acesso em: 06/07/2015. 
BURNS, P. M. Turismo e antropologia: uma introdução. (Trad. Dayse Batista). São Paulo: Chronos, 2002. Coleção Tours.

CAPES. COORDENAÇÃO DE APERFEIÇOAMENTO DE PESSOAL DE NÍVEL SUPERIOR. Banco de Teses e Dissertações 2013. Disponível em:

<http://bancodeteses.capes.gov.br/>. Acesso em: 29/05/2014.

Banco de Teses e Dissertações 2014. Disponível em:

<http://bancodeteses.capes.gov.br/>. Acesso em: 24/07/2015.

COHEN, A. P. The symbolic construction of community. Londres: Routledge, 1985.

DIAS, R. Sociologia do Turismo. São Paulo: Atlas, 2008.

ESMAN, M. R. Tourism as ethnic preservation: the Cajuns of Louisiana. Annals of Tourism Research, v. 11, n. 3, p. 451.467, 1984. Disponível em: <http://www.sciencedirect.com/science/article/pii/0160738384900318>. Acesso em: 25/05/2015.

FARIA, I. F. de. Ecoturismo indígena - território, sustentabilidade, multiculturalismo: princípios para a autonomia. 204 p. Tese de Doutorado, Faculdade de Filosofia, Letras e Ciências Humanas, Universidade de São Paulo, São Paulo, 2008. Disponível em: <http://www.teses.usp.br/teses/disponiveis/8/8135/tde-17022011095412/pt-br.php>. Acesso em: 30/06/2015.

GRABURN, N. Turismo: el viaje sagrado. In: SMITH, V. L. Anfitriones e invitados: antropologia del turismo. Madrid: University of Pennsylvania Press/Ediciones Endymion, 1989, p. 45-68.

GREENWOOD, D. J. La cultura al peso: perspectiva antropologica del turismo en tanto proceso de mercantilizacion cultural. In: SMITH, V. L. Anfitriones e invitados: antropologia del turismo. Madrid: University of Pennsylvania Press/Ediciones Endymion, 1989, p. 257-279.

GRÜNEWALD, R. A. Os "Índios do Descobrimento": tradição e turismo. 350 p. Tese (Doutorado em Antropologia Social), Universidade Federal do Rio de Janeiro/Museu Nacional, Rio de Janeiro, $1999 . \quad$ Disponível em: <http://indiosnonordeste.com.br/wpcontent/uploads/2012/08/TESE-SOBRE-OSPATAX\%C3\%93-BAHIA.pdf>. Acesso em: 04/07/2015.

JESUS, D. J. de. A (re)tradicionalização dos territórios indígenas pelo turismo: um estudo comparativo entre os Kadiwéu (Mato Grosso do Sul- BR) e Maori (Ilha Norte NZ). 265 p. Tese (Doutorado em Geografia), Universidade Federal do Paraná, Curitiba, 2012. Disponível em:

<http://dspace.c3sl.ufpr.br/dspace/bitstream/handle/1884/27396/R\%20-\%20T\%20-

\%20JESUS, \%20DJANIRES\%20LAGEANO\%20DE.pdf?sequence=1>. Acesso em: 04/07/2015. 
LAC, F. O turismo e os Kaingang na Terra Indígena de Iraí/RS. 163 p. Dissertação (Mestrado em Antropologia Social) - Universidade Federal do Paraná, Curitiba, 2005. Disponível em: <http://www.dominiopublico.gov.br/download/texto/cp029037.pdf>. Acesso em: 12/01/2016.

LACERDA, M. A. Perspectivas de desenvolvimento local entre os Terena, na Aldeia Urbana Marçal de Souza, em Campo Grande - MS: a opção pelo etnoturismo. Dissertação de Mestrado, Universidade Católica Dom Bosco, Campo Grande, 2004. Disponível em:

<http://site.ucdb.br/public/md-dissertacoes/7946-perspectivas-de-desenvolvimentolocal-entre-os-terena-na-aldeia-urbana-marcal-de-souza-em-campo-grande-ms-a-opcaopelo-etnoturismo.pdf >. Acesso em: 30/06/2015.

LEANDRO, E. L. Ecoturismo indígena e gestão territorial, contribuições participativas da terra indígena Paiterey Karah (Sete de Setembro). 134 p, Dissertação (Mestrado em Geografia), Universidade Federal de Rondônia, Porto Velho, 2011.

LUSTOSA, I. M. C. Os povos indígenas, o turismo e o território: um olhar sobre os Tremembé e os Jenipapo-Kanindé do Ceará. 281 p. Tese (Doutorado em Geografia), Universidade Federal de Goiás, Goiânia, 2012.

MACCANNELL, D. Reconstructed ethnicity: tourism and cultural identity in Third World communities. Annals of Tourism Research, v. 11, n. 3, 1984, p. 375-391. Disponível em:

<http://www.sciencedirect.com/science/article/pii/0160738384900288>. Acesso em: 25/07/2015.

MALDONADO, C. O turismo rural comunitário na América Latina: Genesis, características e políticas. In: BARTHOLO, R.; SANSOLO, D. G.; BURSZTYN, I. Turismo de Base Comunitária - diversidade de olhares e experiências brasileiras. Rio de Janeiro: Letra e Imagem, 2009. p. 25-44.

MCKEAN, P. F. Hacia un analisis teoretico del turismo: dualidad economica e involucion cultural em Bali. In: SMITH, V. L. Anfitriones e invitados: antropologia del turismo. Madrid: University of Pennsylvania Press/Ediciones Endymion, 1989, p. 189-216.

NASH, D. El turismo considerado como una forma de imperialismo. In: SMITH, V. L. Anfitriones e invitados: antropologia del turismo. Madrid: University of Pennsylvania Press/Ediciones Endymion, 1989. p. 69-91.

NEVES, S. C. A apropriação indígena do turismo: os Pataxó de Coroa Vermelha e a expressão da tradição. 213 p. Tese (Doutorado em Antropologia), Faculdade de Filosofia e Ciências Humanas, Universidade Federal da Bahia, Salvador, 2012. 
NUNES, R. G. A. O turismo como prática social em território indígena: uma análise comparativa entre a Reserva Indígena de Dourados-MS e a aldeia Puiwa Poho em Feliz Natal-MT. Dissertação (Mestrado em Geografia), Universidade Federal de Mato Grosso do Sul, Aquidauana, 2006. Disponível em:

<http://livros01.livrosgratis.com.br/cp120114.pdf>. Acesso em: 02/02/2015.

OLIVEIRA, V. M. de. Turismo, território e modernidade: um estudo da população indígena Krahô, Estado do Tocantins (Amazônia Legal Brasileira). Tese de Doutorado, Faculdade de Filosofia, Letras e Ciências Humanas, Universidade de São Paulo, São Paulo, 2006. Disponível em: <http://www.teses.usp.br/teses/disponiveis/8/8136/tde04062007-160917/pt-br.php>. Acesso em: 30/06/2015.

PEARCE, P. L. A relação entre residentes e turistas: literatura sobre pesquisa e diretrizes de gestão. In: THEOBALD, W. F. (Org.). Turismo Global. (Trad. Ana Maria Capovilla; Maria Cristina Guimarães Cupertino; João Ricardo Barros Penteado). 2. ed. São Paulo: SENAC, 2002. p. 145-164.

RAMOS, K. V. A construção do espaço turístico: trocas simbólicas entre turistas e comunidade Tupinambá em Olivença (Ilhéus - BA). 143 p. Dissertação (Mestrado em Turismo e Cultura), Universidade Estadual de Santa Cruz/ Universidade Federal da Bahia, Ilhéus, 2008. Disponível em:

$<$ http://www.uesc.br/cursos/pos_graduacao/mestrado/turismo/dissertacao/karen_ramos_ pdf.pdf $>$. Acesso em: 04/07/2015.

RUSCHMANN, D. V. de M. Turismo e planejamento sustentável: a proteção do meio ambiente. 14. ed. Campinas: Papirus, 1997.

SANTOS, L. C. Sahu-Apé e o turismo em Terras e comunidades indígenas. 255 p. Dissertação (Mestrado em Antropologia Social), Universidade Federal do Amazonas, Manaus, 2010. Disponível em:

<http://www.ppgas.ufam.edu.br/attachments/article/31/Disserta\%C3\%A7\%C3\%A3o\%2 0-\%20Luciano\%20Cardenes \%20-\%20Sahu-Ap\%C3\%A9.pdf $>$. Acesso em: 04/07/2015.

TALAVERA, A. S. Turismo cultural, culturas turísticas. Horizontes Antropológicos, Porto Alegre, 9 (20), p. 31-57, out. 2003. Disponível em: <http://www.scielo.br/pdf/ha/v9n20/v9n20a02.pdf>. Acesso em: 30/06/2015.

VAN DEN BERGUE, P.; KEYES, C. F. Introduction: tourism and re-created ethnicity. Annals of Tourism Research, 11, p. 43-352, 1984. Disponível em: <http://www.sciencedirect.com/science/article/pii/0160738384900264>. Acesso em: 06/07/2015. 